\title{
Effect of cerium doping on the optical and photocatalytic properties of $\mathrm{ZnO}$ nanoflowers
}

\author{
HEMALATHA PARANGUSAN ${ }^{1}$, DEEPALEKSHMI PONNAMMA ${ }^{1, *}$ (D \\ and MARIAM AL ALI AL-MAADEED ${ }^{2}$ \\ ${ }^{1}$ Center for Advanced Materials, Qatar University, P.O. Box 2713, Doha, Qatar \\ ${ }^{2}$ Materials Science and Technology Program, Qatar University, P.O. Box 2713, Doha, Qatar \\ *Author for correspondence (lekshmi_deepa@yahoo.com)
}

MS received 12 September 2018; accepted 4 February 2019; published online 30 May 2019

\begin{abstract}
Photocatalytic performances of the synthesized cerium doped (Ce-doped) $\mathrm{ZnO}$ nanoflowers are reported in this work. A microwave-assisted sol-gel method is adopted for the synthesis of the nanomaterial and its structural and morphological features are characterized. While doping, the $\mathrm{Ce}^{3+}$ ions occupy the sites of $\mathrm{Zn}^{2+}$ ions in the hexagonal $\mathrm{ZnO}$ lattice, which is investigated by means of X-ray diffraction studies and energy dispersive X-ray analysis. At higher $\mathrm{Ce}^{3+}$ concentrations, ultraviolet (UV) light absorption is quite high as evidenced by the UV-Vis absorption spectra. The photoluminescence study demonstrates higher oxygen vacancy and zinc interstitials for the Ce-doped $\mathrm{ZnO}$ compared to the undoped $\mathrm{ZnO}$. Ce-doping improves the electrical properties of the sample as well. Finally, it is established that the Ce-doped $\mathrm{ZnO}$ nanoflower is highly efficient in UV degrading the methylene blue organic dye.
\end{abstract}

Keywords. Semiconductor; nanoflowers; photoluminescence; defects; microwave-assisted sol-gel method.

\section{Introduction}

Organic dyes are one of the major constituents in several industries like textiles, optoelectronics, food and cosmetics. The exposure of organic waste effluents from industries can greatly affect the environment and its removal is often challenging. In general, chemical coagulation, precipitation, adsorption and membrane filtration techniques are applied for dye removal, particularly from textile wastes [1]. However, most of these methods involve transferring organic compounds from one phase to another and require additional treatments. Nanotechnology has come out as a possible solution for these problems by extending its significance in saving the environment through biodegradation $[2,3]$, recycling [4,5], corrosion inhibition [6,7] and industrial waste management [8]. Recently, nanoparticles as semiconductorbased photocatalysts have been reported for the removal of organic dyes, with their sizes influencing the luminescent and photocatalytic performances $[9,10]$. Among various metal oxides, the wide band gap and large exciton binding energy make zinc oxide $(\mathrm{ZnO})$ a good candidate for photocatalysis. Moreover, its photosensitivity and chemical stability are quite high [11]. However, the photocatalytic activity of this semiconductor can be further enhanced by many methods such as doping with other metal ions, through which the electron-hole $\left(\mathrm{e}^{-} / \mathrm{h}^{+}\right)$recombination rate can be decreased as well $[12,13]$. The reduction in the rate of the $\mathrm{e}^{-} / \mathrm{h}^{+}$recombination and higher photocatalytic activity by doping are mainly attributed to the occupancy of dopant ions in the $\mathrm{ZnO}$ lattice creating more surface defects [14]. The optical properties of $\mathrm{ZnO}$ are enhanced when rare earth metals are doped into it, making the nanomaterial applicable in numerous areas such as biosensors, light emitting diodes, spintronics and photocatalysts. The ultraviolet (UV) absorption and photoluminescence (PL) properties become pronounced by the influence of cerium (Ce)-doping on $\mathrm{ZnO}$ due to the enhancement in charge carriers [15-17]. $\mathrm{Ln}\left(\mathrm{La}^{3+}, \mathrm{Nd}^{3+}\right.$ or $\left.\mathrm{Sm}^{3+}\right)$ doped $\mathrm{ZnO}$ synthesized by the polyacrylamide-gel method reported an enhancement in the photocatalytic activity [18]. The photocatalytic activity of $\mathrm{ZnO}$ nanoparticles was also enhanced by the addition of lanthanum and yttrium ions [19,20]. Out of the several studies practised on the rare earth metal ion doping on $\mathrm{ZnO}$ nanoparticles, doping with the cerium ion has evoked considerable interest because of its promising applications in high-power lasers, light-emitting phosphors and diodes [21-23].

Many methods, such as sol-gel, thermal decomposition, pulsed laser deposition, as well as hydrothermal and chemical reduction, are employed for the synthesis of metal oxide nanoparticles. Among these methods, the microwave-assisted sol-gel method is reported to be a simple and low-cost process compared to conventional heating methods [24-30], since the microwave penetration depth is high and uniform throughout the material $[31,32]$. We have adopted this simple way of nanoparticle synthesis in the current study to synthesize Ce-doped $\mathrm{ZnO}$ nanomaterials. The prepared nanoparticles are well characterized and the influence of $\mathrm{Ce}$-doped $\mathrm{ZnO}$ 
nanoflowers on the photocatalytic degradation (PCD) of organic dye is investigated in detail, and a plausible explanation has been provided to explain their catalytic activity.

\section{Experimental}

\subsection{Preparation of photocatalysts}

Ce-doped $\mathrm{ZnO}$ nanomaterials were synthesized by the previously reported microwave-assisted sol-gel method [33]. The reagents used were obtained from Sigma Aldrich, and were used as such. For the preparation, specific amounts of $\mathrm{Zn}\left(\mathrm{CH}_{3} \mathrm{COO}\right)_{2} \cdot 2 \mathrm{H}_{2} \mathrm{O}$ and cerium(III) chloride heptahydrate $\left(\mathrm{Ce}(\mathrm{Cl})_{3} \cdot 7 \mathrm{H}_{2} \mathrm{O}\right)$ were dissolved in a solution containing $0.5 \mathrm{~g}$ polyvinylpyrrolidone, $3 \mathrm{ml}$ monoethanolamine and $47 \mathrm{ml}$ deionized water. After continuous stirring on a magnetic stirrer, the whole solution in an autoclave was subjected to irradiation with a microwave power of $300 \mathrm{~W}$ [33]. The final suspension obtained after a specific period of irradiation was filtered, washed, dried and calcined for $2 \mathrm{~h}$ at $400^{\circ} \mathrm{C}$ to obtain $\mathrm{Ce}$-doped $\mathrm{ZnO}$. The whole process was repeated by changing the precursor concentration so that $\mathrm{Ce}$-doped $\mathrm{ZnO}$ with different molar ratios $(3,6,9$ and $12 \mathrm{~mol} \%)$ was prepared. To compare the specific properties of Ce-doped $\mathrm{ZnO}$ with those of undoped $\mathrm{ZnO}$, the latter was also synthesized following the same procedure.

\subsection{Characterization techniques}

Both $\mathrm{ZnO}$ and Ce-doped $\mathrm{ZnO}$ samples were analysed using a PANalytical model X'PERT-PRO X-ray powder diffractometer (XRD) equipped with $\mathrm{CuK} \alpha$ radiation with a wavelength of $1.5418 \AA$. Morphologies were examined using the Hitachi S-4200 field emission scanning electron microscope (FESEM) at $15 \mathrm{kV}$ and the JEOL JEM 2011 transmission electron microscope (TEM) at $200 \mathrm{kV}$. The specific surface areas of the nanomaterials were checked from nitrogen absorption data obtained from the micromeritics ASAP 2020 V3.05H and porosity analyser based on the Brunauer-Emmett-Teller (BET) method. The electrical properties of the pelletized samples were further analysed by an AC impedance analyser containing a computer interfaced phase sensitive multimeter (PSM 1735). Band gap analysis was performed using a Shimadzu UV-Vis spectrophotometer (UV-2550) fitted with a diffuse reflectance spectra (DRS) accessory and the PL studies were performed by Perkin Elmer: FLW in a lab LS 55 spectrofluorometer. A Shimadzu UV-Visible double beam spectrophotometer (UV-1700) was used to check the dye concentration. The physico-chemical properties of the model pollutant, methylene blue (MB) dye, is shown in table 1 .

The photocatalytic reaction was performed by the reported procedure [33]. For this, the dye mixed with the nanoparticles was first kept in the dark to achieve the adsorption-desorption equilibrium and thereafter kept in UV irradiation (254 nm)
Table 1. Details of MB dye.

\begin{tabular}{ll} 
Dye & Methylene blue \\
Characteristics & Cationic, water soluble \\
Formula & $\mathrm{C}_{16} \mathrm{H}_{18} \mathrm{~N}_{3} \mathrm{SCl}$ \\
$\lambda_{\max }$ & $665 \mathrm{~nm}$ \\
Applications & Redox indicator, sulphide analy- \\
& sis, peroxide generator \\
\hline
\end{tabular}

within a Heber multi-lamp photoreactor. The dye concentration was monitored at regular intervals of time using the UV-Vis spectrophotometer. A decrease in concentration of the dye was marked by a decrease in the absorption peak intensity at $660 \mathrm{~nm}$. The PCD efficiency $(\eta)$ was also calculated using equation (1):

$$
\eta=\frac{\left(C_{\mathrm{i}}-C_{\mathrm{t}}\right)}{C_{\mathrm{i}}} \times 100
$$

where $C_{\mathrm{i}}$ is the initial dye concentration and $C_{\mathrm{t}}$ the final concentration after $t$ min.

\section{Results and discussion}

\subsection{Crystallinity studies}

XRD patterns of Ce-doped $\mathrm{ZnO}$ are compared with those of undoped $\mathrm{ZnO}$ as shown in figure 1 . The diffraction peaks due to the undoped $\mathrm{ZnO}$ observed at $31.67,34.41,36.26,47.64$, $56.62,62.87,67.86$ and $69.10^{\circ}$, respectively, correspond to the (100), (002), (101), (102), (110), (103), (112) and (201) hexagonal planes (JCPDS card no: 79-0208). From figure 1a, no diffraction peaks are observed for the cerium compounds up to an addition of $3 \mathrm{~mol} \%$. But at a higher cerium concentration, a new peak at $2 \theta, 28.67^{\circ}$ related to $\mathrm{CeO}_{2}$ appears in the spectrum (JCPDS card no: 81-0792). This corresponds to the (111) plane for the $\mathrm{CeO}_{2}$ crystalline structure and shows the formation of the secondary phase of $\mathrm{CeO}_{2}$ at a higher concentration of $\mathrm{Ce}^{3+}$ ions. This is because of the limited $\mathrm{Ce}^{3+}$ ion solubility in the host $\mathrm{ZnO}$ spinel lattice [34]. Figure $1 \mathrm{~b}$ shows the effect of Ce-doping on $\mathrm{ZnO}$ crystallinity. Diffraction peaks corresponding to (100), (002) and (101) planes for $\mathrm{Ce}$-doped $\mathrm{ZnO}$ samples are slightly shifted to lower angles compared to the undoped $\mathrm{ZnO}$. In addition, the intensity of the diffraction peaks is decreased, confirming the presence of $\mathrm{Ce}^{3+}$ ions in the $\mathrm{ZnO}$ lattice.

The average crystallite size can be calculated using Scherrer equation (2) [35]:

$$
D=\frac{0.9 \lambda}{\beta \cos \theta},
$$



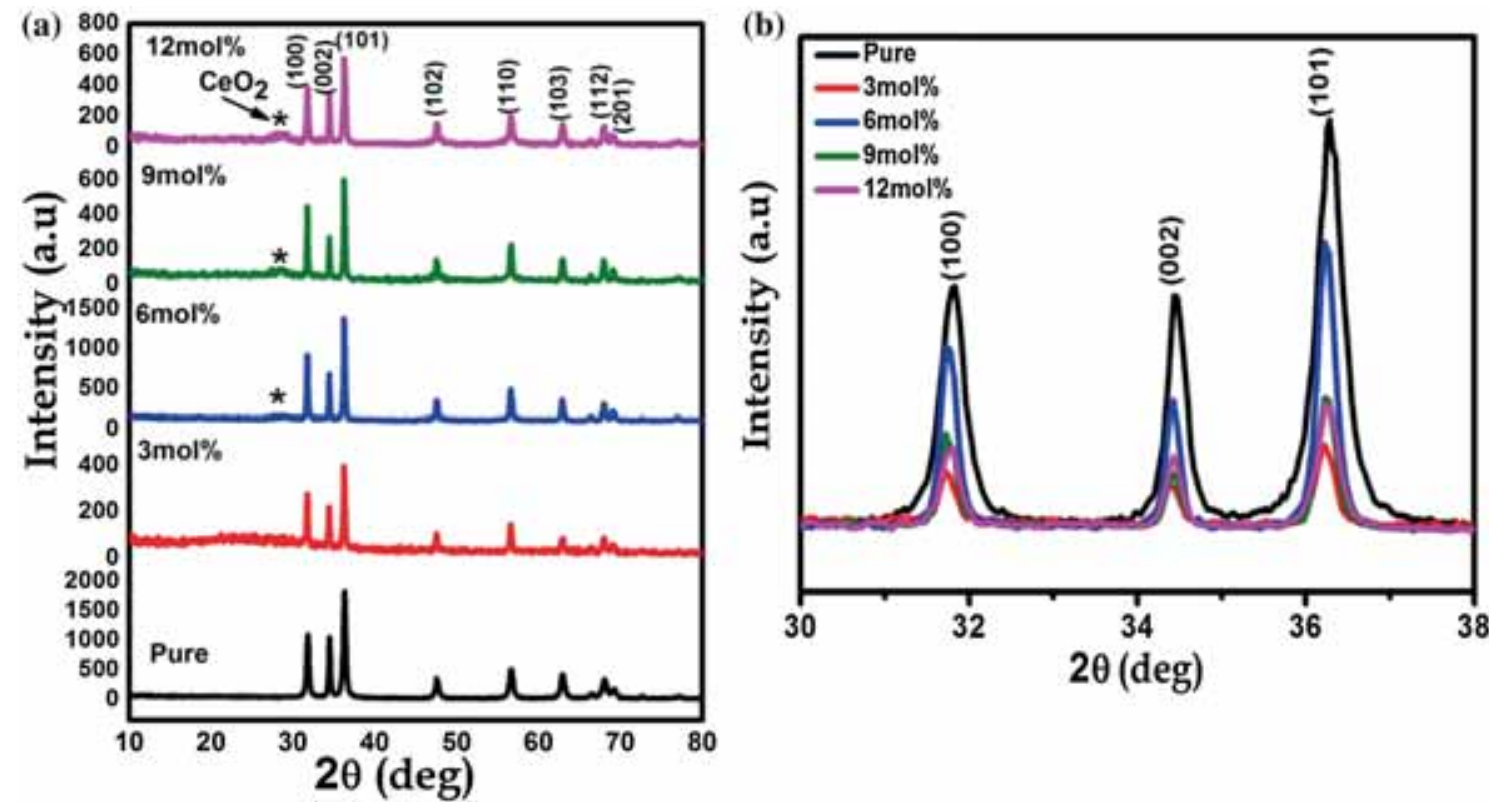

Figure 1. (a) XRD spectra and (b) (100), (002) and (101) peak positions for the $\mathrm{ZnO}$ and Ce-doped $\mathrm{ZnO}$ nanostructures.

Table 2. Calculated lattice parameters, size of the crystallites and band gap of the $\mathrm{ZnO}$ and Ce-doped $\mathrm{ZnO}$ nanostructures.

\begin{tabular}{lccccc}
\hline & \multicolumn{3}{c}{ Lattice parameters } & & \\
Samples & $a(\AA)$ & $c(\AA)$ & $c / a$ ratio & $\begin{array}{c}\text { Debye-Scherrer } \\
\text { crystallite size (nm) }\end{array}$ & Band gap (eV) \\
\cline { 2 - 5 } $\mathrm{ZnO}$ & 3.249 & 5.204 & 1.601 & 22 & 3.15 \\
$3 \mathrm{~mol} \% \mathrm{Ce}-\mathrm{ZnO}$ & 3.252 & 5.209 & 1.601 & 34 & 3.12 \\
$6 \mathrm{~mol} \% \mathrm{Ce}-\mathrm{ZnO}$ & 3.253 & 5.210 & 1.601 & 33 & 3.10 \\
$9 \mathrm{~mol} \% \mathrm{Ce}-\mathrm{ZnO}$ & 3.253 & 5.211 & 1.601 & 30 & 3.08 \\
$12 \mathrm{~mol} \% \mathrm{Ce}-\mathrm{ZnO}$ & 3.255 & 5.214 & 1.601 & 22 & 3.03 \\
\hline
\end{tabular}

where $D$ represents the average crystallite size, $\lambda$ is the wavelength of X-rays; $\beta$ is the full width at half maximum and $\theta$ is the scattering angle.

According to Bragg's law, the lattice constants $a$ and $c$ were calculated by the following relation (3) [36]:

$$
\frac{1}{d_{(h, k, l)}^{2}}=\frac{4}{3}\left(\frac{h^{2}+h k+k^{2}}{a^{2}}\right)+\frac{l^{2}}{c^{2}}
$$

The calculated lattice parameters and crystallite sizes of the nanoparticles are shown in table 2 . It is clear that the crystallite size of $\mathrm{ZnO}$ increases from 22 to $34 \mathrm{~nm}$ when it is doped with $3 \mathrm{~mol} \%$ cerium, and further doping at 6,9 and $12 \mathrm{~mol} \%$ decreases the crystallite size. It is well known that the crystallite size contributions to XRD line broadening are independent of each other. The decreased crystallite size can be explained by the interruption in movement of the grain boundaries by the Zener pinning effect [37]. Here, the presence of $\mathrm{Ce}$ ions in $\mathrm{ZnO}$ prevents the growth of crystal grains and slows down the motion of the grain boundary. This causes a retarding force on the boundaries such that if this force is more than the driving force for grain growth, the particles cannot grow any longer [38,39]. The larger crystallite size at $3 \mathrm{~mol} \% \mathrm{Ce}$-doping can be due to the Ostwald ripening effect, in which relatively larger particles grow at the expense of the smaller ones [40]. Based on Vegard's law, the lattice parameters show an increase, corresponding linearly to the $\mathrm{Ce}^{3+}$ concentration [41]. Also, the ionic radius of $\mathrm{Zn}^{2+}(0.74 \AA)$ is smaller than that of $\mathrm{Ce}^{3+}$ ions $(1.03 \AA)$. The observed lattice parameter values for both $\mathrm{ZnO}$ and Ce-doped $\mathrm{ZnO}$ are in good agreement with the JCPDS card no: 79-0208.

\subsection{Morphology studies}

Figure 2 illustrates the SEM images for the Ce-doped $\mathrm{ZnO}$ and confirms its flower like morphology. Similar morphologies are observed for the undoped $\mathrm{ZnO}$ as well $[33,42]$. These 

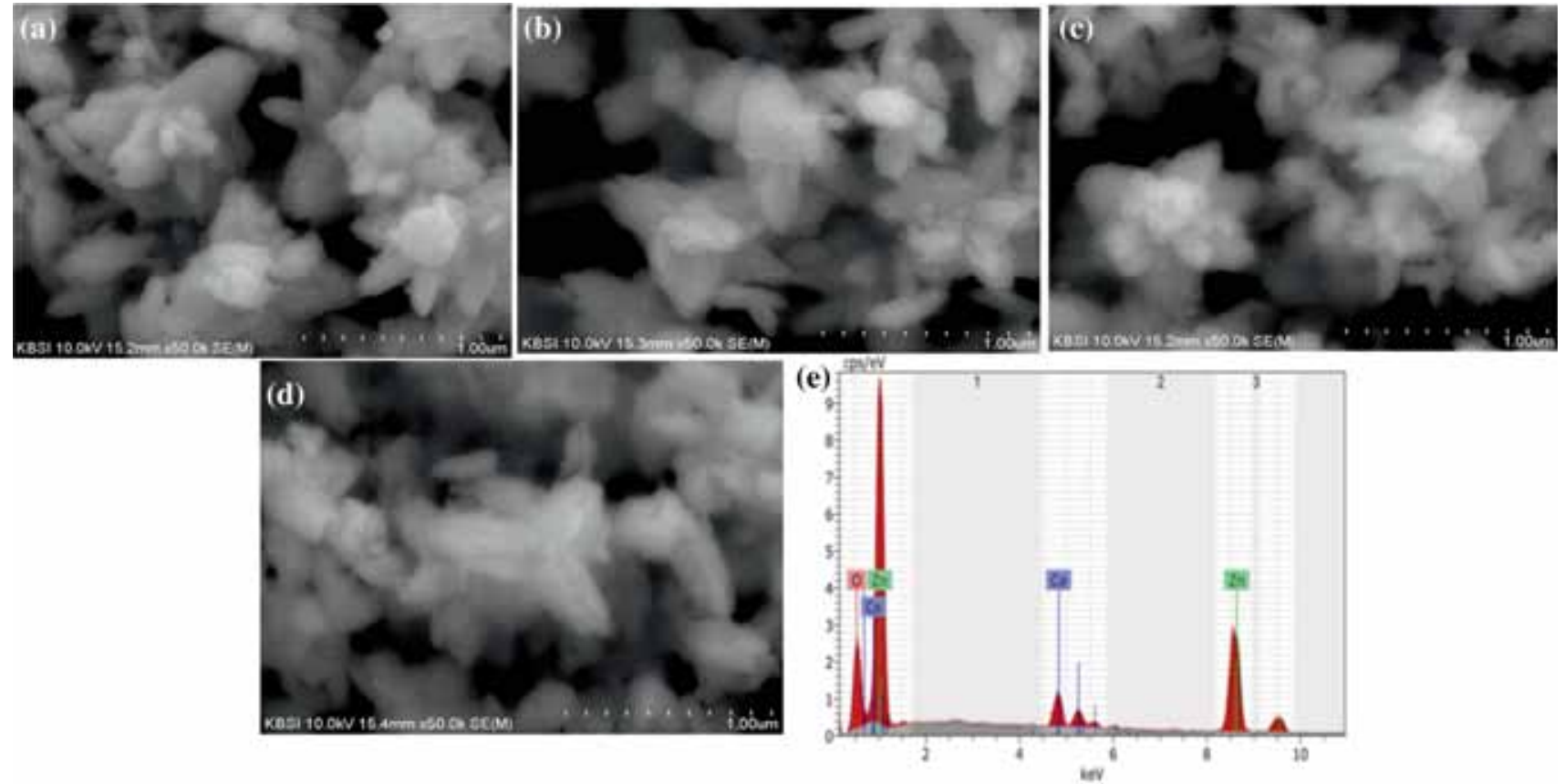

Figure 2. SEM images of Ce-doped $\mathrm{ZnO}$ at various mol\%: (a) $3 \mathrm{~mol} \%$, (b) $6 \mathrm{~mol} \%$, (c) $9 \mathrm{~mol} \%$, (d) $12 \mathrm{~mol} \%$ and (e) $\mathrm{EDX}$ spectrum of $12 \mathrm{~mol} \%$ Ce-doped $\mathrm{ZnO}$.

pieces of evidence show that the $\mathrm{Ce}^{3+}$ ion incorporation has not disturbed the $\mathrm{ZnO}$ lattice.

The flower like morphology is mainly attributed to the addition of monoethanolamine which serves as an intermediate complex. The elemental analysis (EDX) spectrum for the $12 \mathrm{~mol} \% \mathrm{Ce}$-doped $\mathrm{ZnO}$ sample is illustrated in figure 2e. This spectrum indicates the presence of $\mathrm{Zn}, \mathrm{Ce}$ and $\mathrm{O}$ atoms as the major chemical components in the Ce-doped $\mathrm{ZnO}$. This observation indicated the absence of any impurity in the Cedoped $\mathrm{ZnO}$ nanoflowers.

Further information about the morphology is explored by means of TEM images shown in figure 3. The undoped $\mathrm{ZnO}$ and all $\mathrm{Ce}$-doped $\mathrm{ZnO}$ samples exhibit a nanoflower like morphology [42]. This illustrates that the $\mathrm{ZnO}$ lattice is not affected by the $\mathrm{Ce}^{3+}$ ions.

Parameters such as the average diameter of the nanorods, shape and number of petals of the pure $\mathrm{ZnO}$ and Ce-doped $\mathrm{ZnO}$ nanoflowers are compared in table 3 . It is notable that the average diameter enhances first and then decreases with the percentage of cerium doping. In addition, the undoped $\mathrm{ZnO}$ shows an agglomerated flower like morphology, whereas with cerium doping, the petals for flowers begin to form.

The high-resolution transmission electron microscopy (HRTEM) pattern (figure 4a) representing nanocrystalline structures of the $12 \mathrm{~mol} \% \mathrm{Ce}$-doped $\mathrm{ZnO}$ shows the pinning of two domains having two different orientations, i.e., the (002) plane with a $d$-spacing of $2.6 \AA$ and the (111) plane with a $d$-spacing of $3.1 \AA$ due to the effect of Ce-dopant concentration on the $\mathrm{ZnO}$ lattice, whereas in the undoped case the (002) planes were present with inter-planar $d$-spacing, $2.6 \AA$
[42]. The selected area electron diffraction patterns (SAED) for the $12 \mathrm{~mol} \% \mathrm{Ce}$-doped $\mathrm{ZnO}$ (figure $4 \mathrm{~b}$ ) also confirms the crystallinity of the sample.

In order to explain the formation of flower shaped Cedoped $\mathrm{ZnO}$ nanostructures, a possible formation mechanism is proposed as shown in figure 5. Monoethanolamine plays an important role in the growth of Ce-doped $\mathrm{ZnO}$ nanostructures. This precursor initiates the formation of many amorphous seed nuclei within the nanostructure, which further grow to longer rods. In other words, the growth is by the well-known Ostwald ripening effect in which the growth of a large particle occurs at the expense of smaller ones. This mechanism occurs quite easily when dispersed in a solvent, and the various sub-units of grown nanoparticles are interconnected by the orientation attachment process to derive the nanoflower architecture [43].

To investigate the specific surface area and porosity of the undoped- $\mathrm{ZnO}$ and Ce-doped $\mathrm{ZnO}$ samples, the $\mathrm{N}_{2}$ adsorption-desorption isotherm measurements are conducted. The BET surface areas of undoped- $\mathrm{ZnO}$ and $12 \mathrm{~mol} \%$ Ce-doped $\mathrm{ZnO}$, respectively, give the values 6.6168 and $12.03 \mathrm{~m}^{2} \mathrm{~g}^{-1}$. These specific surface area values are comparable. In addition, the specific pore volume of the $12 \mathrm{~mol} \%$ Ce-doped $\mathrm{ZnO}$ sample is $0.023 \mathrm{~cm}^{3} \mathrm{~g}^{-1}$, as revealed in the Barrett-Joyner-Halenda plot (inset figure 6). Figure 6 shows the representative $\mathrm{N}_{2}$ adsorption-desorption isotherms of $\mathrm{ZnO}$ and $12 \mathrm{~mol} \% \mathrm{Ce}$-doped $\mathrm{ZnO}$ samples. It showed a type II isotherm with a large type hysteresis loop [44]. The formation of the hysteresis loop in the adsorption-desorption isotherm of the Ce-doped sample indicates its non-porous nature. The 

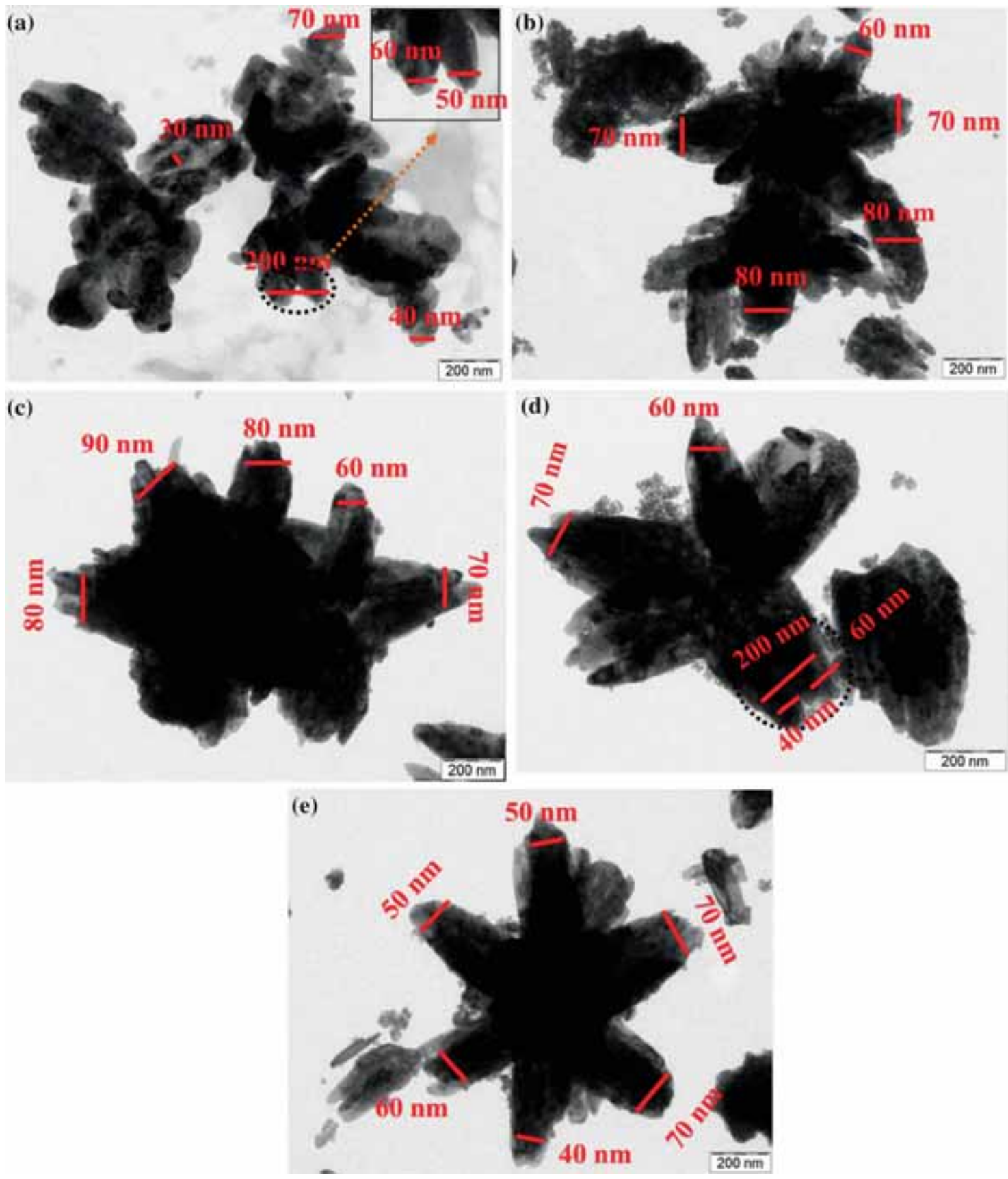

Figure 3. (a) TEM image of pure $\mathrm{ZnO}$ and (b-e) 3, 6, 9, 12 mol\% Ce-doped $\mathrm{ZnO}$ samples.

Table 3. Comparison of average diameter, shape and number of petals.

\begin{tabular}{lccc}
\hline Sample & Average diameter $(\mathrm{nm})$ & Shape & Number of petals \\
\hline $\mathrm{ZnO}$ & $30-70$ & Agglomerated flowers & 2 \\
$3 \mathrm{~mol} \% \mathrm{Ce}-\mathrm{ZnO}$ & $60-80$ & Agglomerated flowers & 6 \\
$6 \mathrm{~mol} \% \mathrm{Ce}-\mathrm{ZnO}$ & $60-90$ & Flower shape & 5 \\
$9 \mathrm{~mol} \% \mathrm{Ce}-\mathrm{ZnO}$ & $40-70$ & Flower shape & 4 \\
$12 \mathrm{~mol} \% \mathrm{Ce}-\mathrm{ZnO}$ & $40-70$ & Flower shape & 6 \\
\hline
\end{tabular}



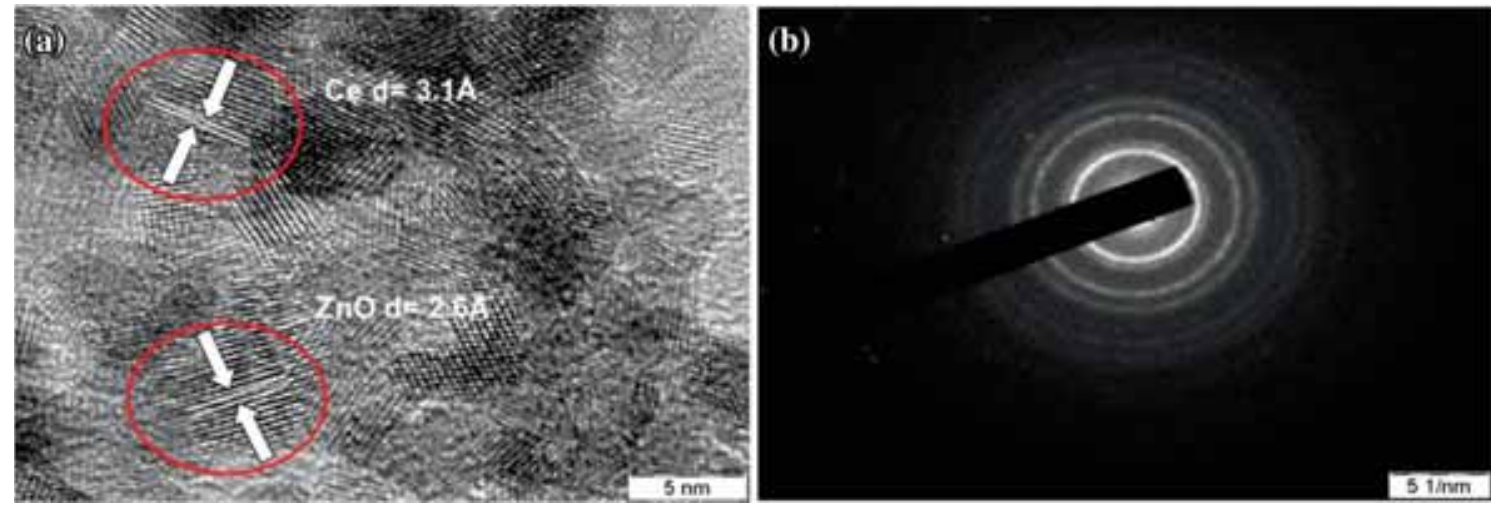

Figure 4. (a) HRTEM image and (b) SAED pattern of $12 \mathrm{~mol} \%$ of Ce-doped $\mathrm{ZnO}$.

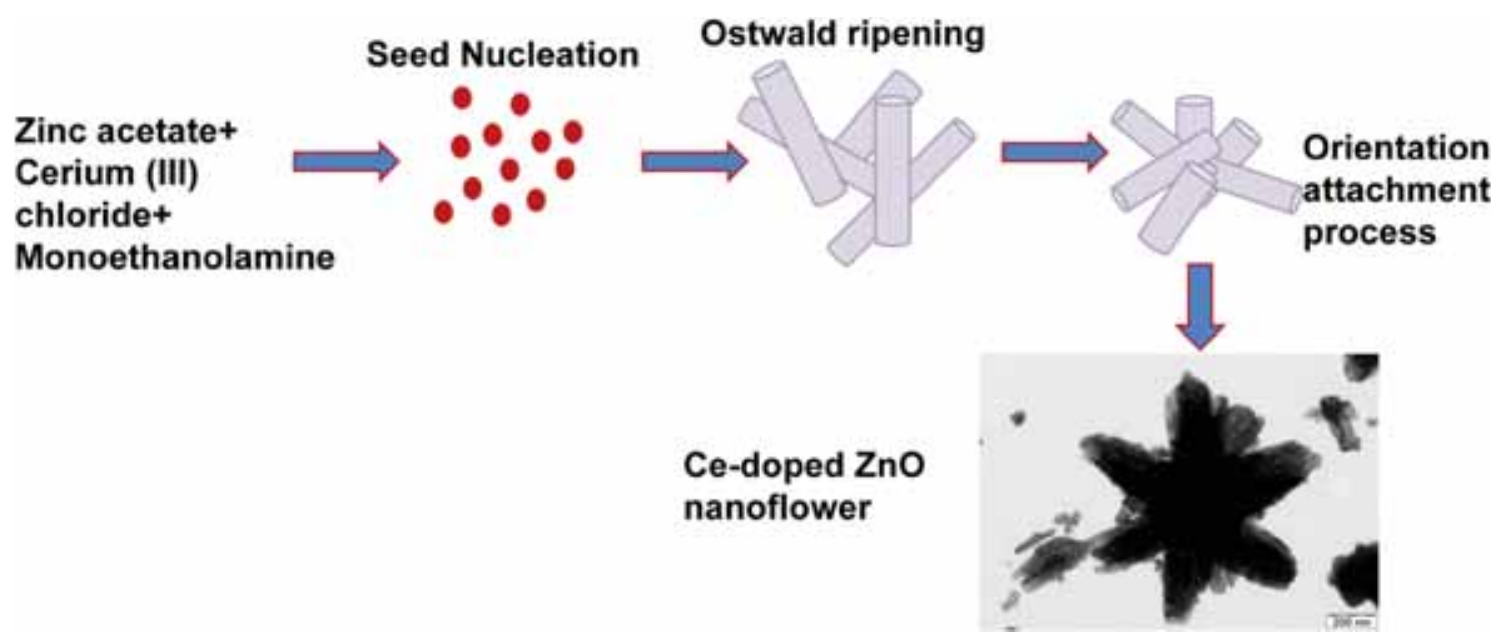

Figure 5. Possible formation mechanism of flower-like Ce-doped $\mathrm{ZnO}$ sample.

results reveal the influence of $\mathrm{Ce}^{3+}$ doping in enlarging the surface area.

\subsection{Electrical property investigation}

Impedance spectroscopy analysis is a powerful technique for determining the electrical properties of the samples. Figure $7 \mathrm{a}$ shows the Nyquist plots and figure $7 \mathrm{~b}$ shows the variation of the dielectric constant with frequency for the undoped- $\mathrm{ZnO}$ and $\mathrm{Ce}$-doped $\mathrm{ZnO}$ samples.

All the samples exhibit semicircular curves in a higher frequency region (figure 7a). This indicates the presence of $\mathrm{Ce}^{3+}$ ions in the $\mathrm{ZnO}$ lattice. The semicircle at high frequencies is related to the interfacial charge transfer resistance. The semicircle or electron transfer resistance has decreased for the Ce-doped $\mathrm{ZnO}$, which suggests the incorporation of $\mathrm{Ce}^{3+}$ ions into the $\mathrm{ZnO}$ lattice thus making the process of electron transfer easier [45].

Figure $7 \mathrm{~b}$ shows the frequency dependence of the dielectric constant $\varepsilon^{\prime}$ at room temperature for the $\mathrm{ZnO}$ and $\mathrm{Ce}$-doped
$\mathrm{ZnO}$. From the spectra, it can be seen that the dielectric constants are high in the low frequency region, whereas those in the higher frequency side decrease. It is evident that the dielectric constant is greater for the doped samples compared to the undoped- $\mathrm{ZnO}$. This is because of the increase in dipole moment of the Ce-doped systems. The better dielectric properties support the applicability of $\mathrm{Ce}$-doped $\mathrm{ZnO}$ in charge storage devices and in photocatalysis [46].

\subsection{UV-Vis DRS analysis}

The optical parameters are very important to verify how the $\mathrm{Ce}$ doping on $\mathrm{ZnO}$ affects their absorption properties. Figure 8 a shows the UV-Vis DRS of $\mathrm{ZnO}$ and Ce-doped $\mathrm{ZnO}$ nanoflowers. The optical absorption is recorded in the range of $300-800 \mathrm{~nm}$ by the UV-Vis spectrophotometer.

A strong absorption band is observed at $361 \mathrm{~nm}$. It is interesting to note that the absorption of $\mathrm{ZnO}$ peaks increases considerably above this region and in comparison with that of undoped- $\mathrm{ZnO}$, the optical absorption edges of the $\mathrm{Ce}$ doped $\mathrm{ZnO}$ samples are shifted towards the longer wavelength 


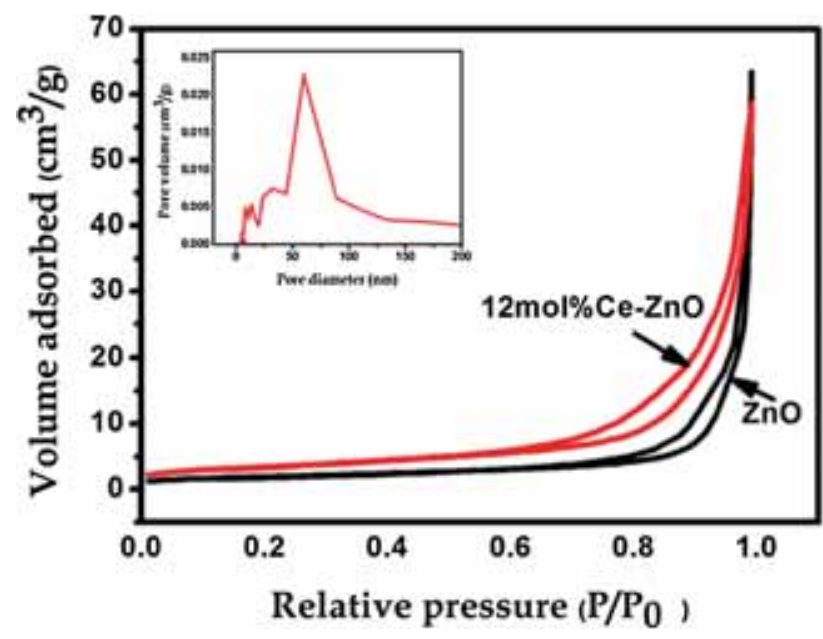

Figure 6. BET isotherms of $\mathrm{ZnO}$ and $12 \mathrm{~mol} \% \mathrm{Ce}$-doped $\mathrm{ZnO}$ nanoflower.

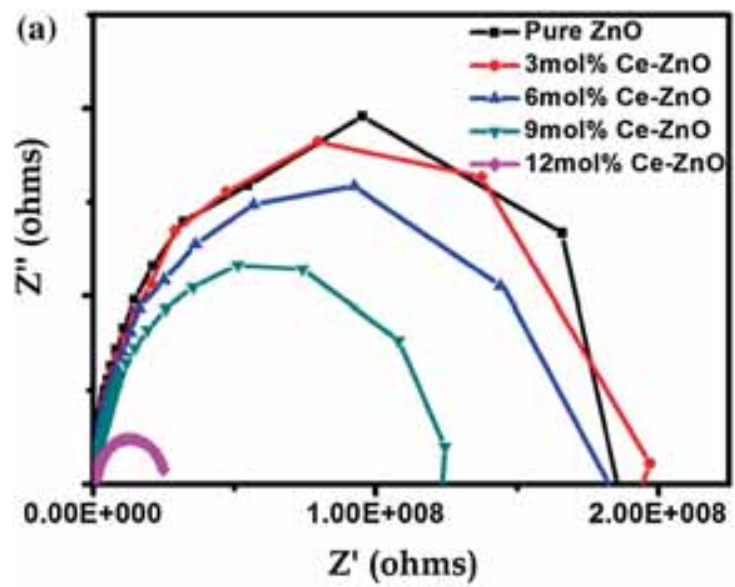

region. This red shift is attributed to the presence of $\mathrm{Ce}^{3+}$ ions, and charge transfer transitions occurring between the lanthanide ' $\mathrm{f}$ ' electrons and the conduction band/valence band (CB/VB) of $\mathrm{ZnO}$.

The band gap of the nanomaterials is calculated by equation (4)

$$
\alpha h v=A\left(h v-E_{\mathrm{g}}\right)^{n},
$$

where $\alpha$ is the absorption coefficient. Values of ' $n$ ' are different for different types of transitions. It is equal to $1 / 2$ for the allowed direct transition and 2 for the allowed indirect transition. But $n$ takes the values of $3 / 2$ and 3 for the direct and indirect forbidden transitions, respectively. ' $A$ ' is a temperature independent constant and it corresponds to the band tailing. Tauc's plots (figure $8 \mathrm{~b}$ ) are drawn as the variation of $(\alpha h v)^{2} v s$. photon energy $(h v)$ in which the $X$-intercept of the

Figure 7. (a) Nyquist plots and (b) dielectric constant $v s . \log f$ plots of $\mathrm{ZnO}$ and Ce-doped $\mathrm{ZnO}$ samples.

(a)

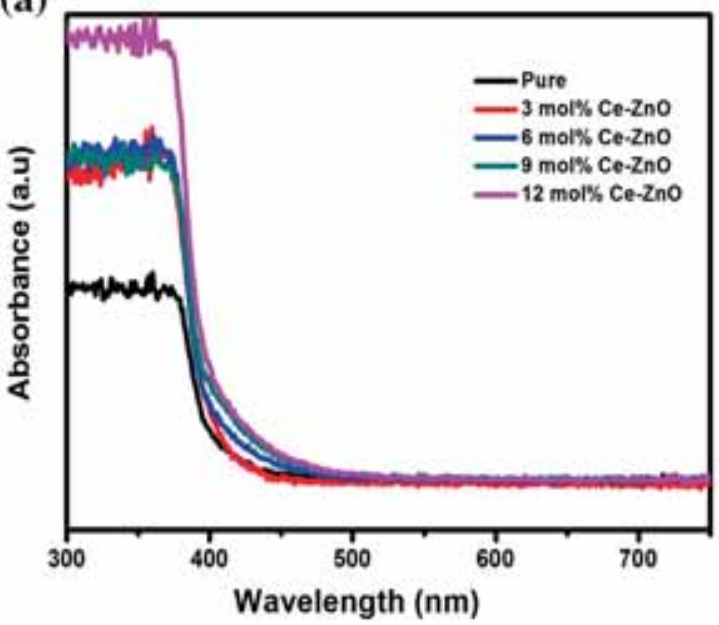

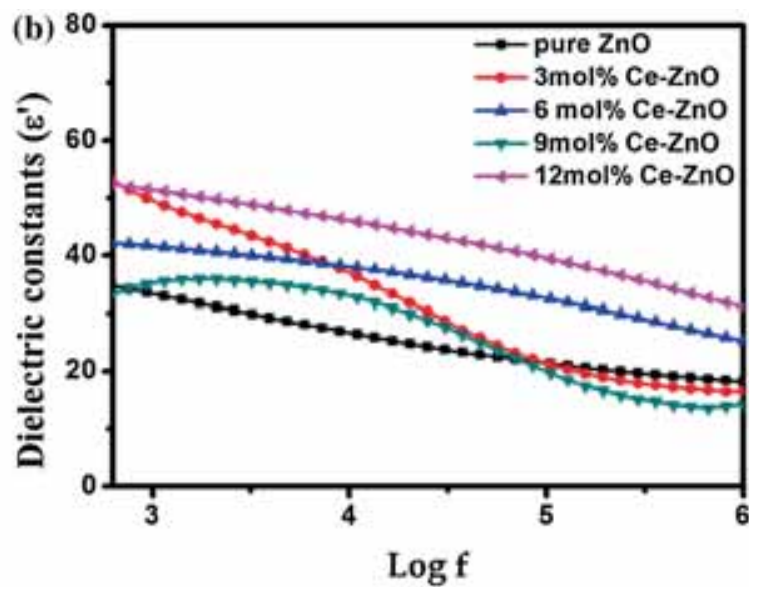

(b)

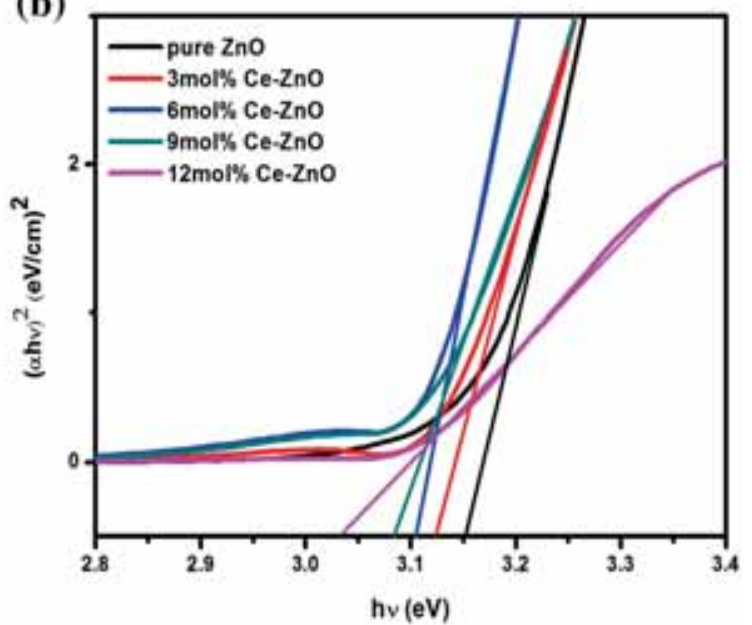

Figure 8. Variation of (a) absorbance with wavelength and (b) $(\alpha h v)^{2}$ with $h v$ for the $\mathrm{ZnO}$ and Ce-doped $\mathrm{ZnO}$. 
tangent marks the direct band gap $\left(E_{\mathrm{g}}\right)$ of the photocatalysts. The $E_{\mathrm{g}}$ values are shown in table 2 . The $E_{\mathrm{g}}$ value shifts to the shorter or longer wavelength sides depending on the size and the dopant ions in different forms. It can be seen that the $E_{\mathrm{g}}$ value decreases as the dopant concentration increases. Therefore, the decrease in the $E_{\mathrm{g}}$ value of the samples can be attributed to the presence of the $\mathrm{Ce}_{2} \mathrm{O}_{3}$ secondary phase. The red shift of the photocatalyst can also be ascribed to the charge transfer between the $\mathrm{ZnO} \mathrm{VB}$ or $\mathrm{CB}$ and the cerium ion in the $4 \mathrm{f}$ level [47].

During Ce doping, the photoelectron trap centres are formed and these are accompanied by the formation of defects. Liu et al [48] proposed that the red shift of the absorption edges accounts for a large number of surface defect states. These defect states help to enhance the photocatalytic behaviour of the synthesized Ce-doped $\mathrm{ZnO}$ materials.

The dopant induced red shift and increased absorption intensity can be attributed to the increased rate of the electron-hole pair formation on the photocatalyst surface. This electron-hole recombination results in higher photocatalytic activity of the photocatalysts [49].

\subsection{PL studies}

The PL spectra of $\mathrm{ZnO}$ and $\mathrm{Ce}$-doped $\mathrm{ZnO}$ samples at the excitation wavelength of $325 \mathrm{~nm}$ are represented in figure 9.

Generally, PL emission for metal oxide nanostructures possesses a near-band edge (NBE) UV emission and deep level (DL) defect associated with the visible emission that are closely related to the surface states, oxygen vacancies and defects [50]. As shown in figure 9, a strong UV band gap emission takes place at $391 \mathrm{~nm}$ due to the radiative recombination of the VB hole and the excited $\mathrm{CB}$ electron. Visible or deep trap state emissions (411, 444, 485, 491 and $521 \mathrm{~nm}$ ) commonly defined as the electron-hole pair recombination from localized states with energy levels deep in the band gap are lower energy emissions [51] and are caused by

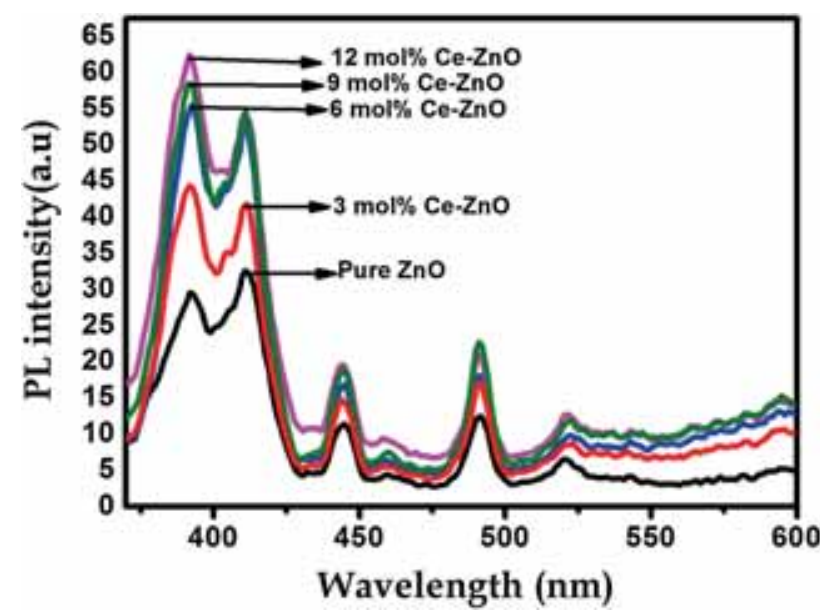

Figure 9. $\mathrm{PL}$ spectra of $\mathrm{ZnO}$ and $\mathrm{Ce}$-doped $\mathrm{ZnO}$ nanostructures. different intrinsic defects in $\mathrm{ZnO}$, such as ionic vacancy (oxygen/zinc), interstitial ions and antisite oxygen [52]. While the violet emission $(411 \mathrm{~nm})$ is due to the surface zinc vacancy [53], the blue emission (444 and $491 \mathrm{~nm}$ ) peak comes from the simply trapped electrons at the interface lying within the depletion regions of $\mathrm{ZnO}$ grain boundaries [54]. The green emission $(521 \mathrm{~nm})$ comes from the energy gap between the levels of oxygen vacancy and the valence band [52]. The $\mathrm{Ce}$ doped $\mathrm{ZnO}$ nanostructures show high PL intensities compared to $\mathrm{ZnO}$ indicating higher oxygen vacancies and other defects in the former. It is also due to the high separation rate of photoinduced charge carriers and higher electron-hole separation [55]. This will help to enhance the photocatalytic activity.

\subsection{Photocatalytic activity}

The heterocyclic and aromatic compound, $\mathrm{MB}$ dye, is 3,7bis(dimethylamine)-phenothiazine-5-iumchloride $\left(\mathrm{C}_{16} \mathrm{H}_{18} \mathrm{~N}_{3}\right.$ $\mathrm{SCl})$. The $\mathrm{MB}$ powder is soluble in water and it is mainly used for applications related to environmental science and chemistry [56]. Here, the degradation process of $\mathrm{MB}$ dye using undoped- $\mathrm{ZnO}$ and $\mathrm{Ce}$-doped $\mathrm{ZnO}$ was investigated under $\mathrm{UV}$ light irradiation.

Figure 10 shows the influence of time on the MB dye degradation in the presence of $\mathrm{ZnO}$ and $\mathrm{Ce}$-doped $\mathrm{ZnO}$ systems under UV light irradiation. The percentage of dye degradation is calculated based on the UV absorbance values as follows:

$$
D(\%)=\frac{\left(A_{0}-A\right)}{t}
$$

where $D$ is the dye degradation percentage, $A_{0}$ is the initial absorbance and $A$ is the absorbance at time $t$. The characteristic UV absorption peak of MB at $665 \mathrm{~nm}$ decreases in intensity with an increase in irradiation time, and this is clear from the increased percentage of dye removal with time. Compared to $\mathrm{ZnO}$ nanoparticles, the $\mathrm{Ce}$-doped $\mathrm{ZnO}$ nanoparticles show

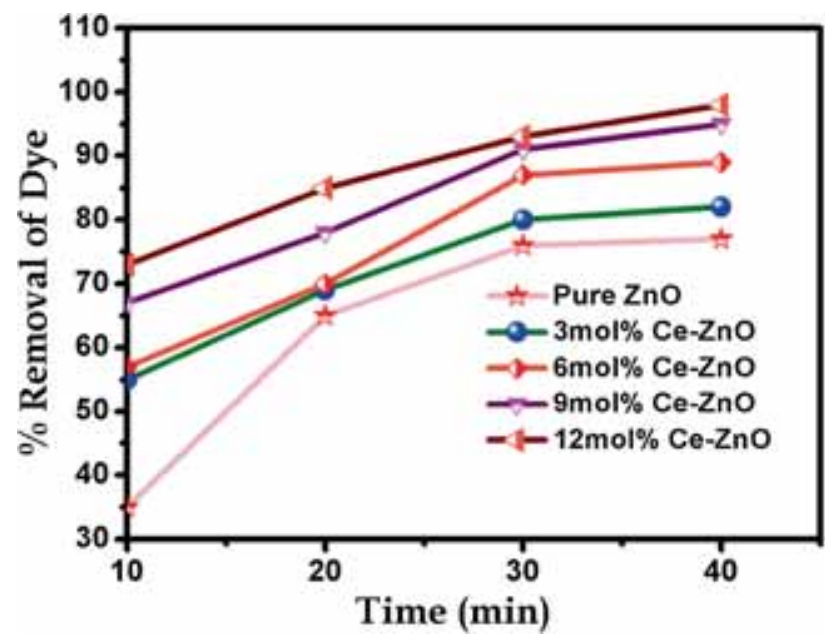

Figure 10. Variation in the degradation of dye with time. 
better photocatalytic performances. A close look at figure 10 illustrates that the $12 \mathrm{~mol} \% \mathrm{Ce}$-doped $\mathrm{ZnO}$ nanoparticles drastically decrease the absorbance of MB dye with an increase of irradiation time. This sample exhibits the best PCD (94\%) in $50 \mathrm{~min}$.

In metal-oxide semiconductors, the photocatalytic activity typically depends on the morphologies [57], particle size [58] and surface properties [59]. In the present system, the higher photodegradation efficiency of the Ce-doped $\mathrm{ZnO}$ is explained on the basis of surface defects. Both the undoped and dopednanoparticles show similar morphologies and particle sizes; however, the particle sizes of the former are smaller than those of the latter. Moreover, the higher surface defects of the doped samples are clearly shown in figure 9, which confirms the enhanced photocatalytic activity. This is also explained based on the electron-hole pair recombination ratios. The defects on the surface of the catalyst create numerous photogenerated electron-hole pairs. More surface defects, such as oxygen vacancies and zinc interstitials, were attributed to the lower recombination between photo-generated electrons and holes with oxygen vacancies serving as electron traps [60]. This results in better dye degradation upon optimum cerium ion doping in the $\mathrm{ZnO}$ lattice.

3.6a Decolouration kinetics: Figure 11 represents the photocatalytic dye degradation that obeys the pseudo-first order kinetics. The regression curve of the natural logarithm of $C_{0} / C_{\mathrm{t}} v s$. illumination time gives a straight line. This plot suggests that the photo-decolouration reaction approximately follows the pseudo-first order kinetics as represented by equation (6)

$$
\ln \left(\frac{C_{0}}{C_{\mathrm{t}}}\right)=K t,
$$

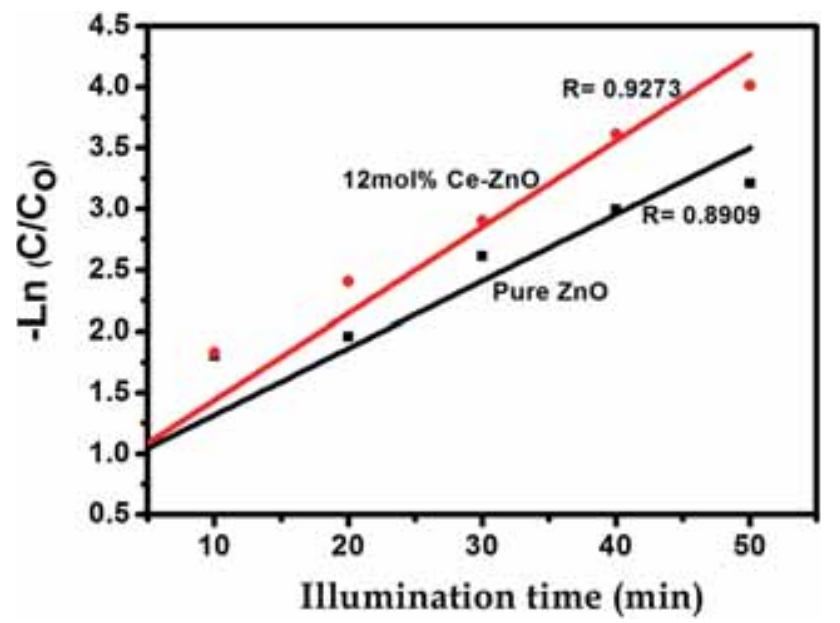

Figure 11. Pseudo-first order kinetics of the degradation of MB using undoped- $\mathrm{ZnO}$ and $12 \mathrm{~mol} \%$ of Ce-doped $\mathrm{ZnO}$ under UV light.

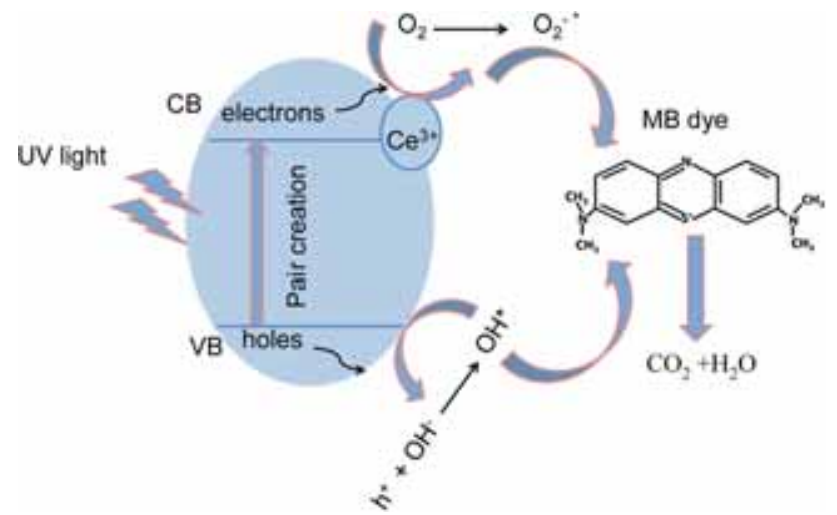

Figure 12. Formation of hydroxyl and superoxide radicals under UV light irradiation.

where $C_{0}$ is the initial concentration of the dye and $C_{\mathrm{t}}$ is the concentrations at various time intervals. $K$ is the pseudo-first order constant for degradation of the dye and $t$ is the irradiation time [61].

3.6b The photo-catalytic degradation mechanism: Figure 12 illustrates the plausible reaction mechanism proposed for the photo-degradation of dye by the $\mathrm{Ce}$-doped $\mathrm{ZnO}$ sample. The generation of electron-hole $\left(\mathrm{e}^{-}-\mathrm{h}^{+}\right)$pairs between the VB and $\mathrm{CB}$ of $\mathrm{Ce}$-incorporated $\mathrm{ZnO}$ provides the driving force for the $\mathrm{e}^{-} / \mathrm{h}^{+}$movement, in turn a better degradation activity of $\mathrm{MB}$ dye. $\mathrm{ZnO}$ particles upon irradiation with photons cause for the excitation of an $\mathrm{e}^{-}$from its VB to the CB leaving behind a positively charged $\mathrm{h}^{+}$in the VB [33]. Thus, the generated charge carriers can recombine on the surface of Ce-doped $\mathrm{ZnO}$, serving as oxidizing and redox sources as represented by the electron donor/acceptor in equation (7).

$$
\begin{aligned}
& \mathrm{Zn}_{1-x} \mathrm{Ce}_{x} \mathrm{O}+h v \rightarrow \mathrm{Zn}_{1-x} \mathrm{Ce}_{x} \mathrm{O}\left(\mathrm{h}_{\mathrm{VB}}^{+}\right) \\
& \quad+\mathrm{Zn}_{1-x} \mathrm{Ce}_{x}\left(\mathrm{e}_{\mathrm{CB}}^{-}\right)
\end{aligned}
$$

The $\mathrm{VB} \mathrm{h}^{+}$reacts with the chemisorbed $\mathrm{H}_{2} \mathrm{O}$ molecules to form reactive species such as hydroxyl $\left(\mathrm{OH}^{\bullet}\right)$ radicals. Likewise, $\mathrm{CB} \mathrm{e}^{-}$results in the formation of superoxide $\left(\mathrm{O}_{2}^{\bullet}\right)$ radicals by the trapping of electrons by oxygen atom. The generated $\mathrm{O}_{2}^{\bullet-}$ then further combines with $\mathrm{H}^{+}$to produce $\mathrm{HO}_{2}^{\bullet}$, which can react with the trapped electrons to generate $\mathrm{OH}^{\bullet}$ radicals [51]. The highly reactive hydroxyl radicals then attack organic compounds. Finally, the degradation product is obtained as per equations (8-14).

$$
\begin{aligned}
& \mathrm{Zn}_{1-x} \mathrm{Ce}_{x} \mathrm{O}\left(\mathrm{h}_{\mathrm{VB}}^{+}\right)+\mathrm{H}_{2} \mathrm{O} \rightarrow \mathrm{H}^{+}+\mathrm{OH}^{\bullet} \\
& \mathrm{H}_{2} \mathrm{O} \leftrightarrow \mathrm{H}^{+}+\mathrm{OH}^{-} \\
& \mathrm{Zn}_{1-x} \mathrm{Ce}_{x} \mathrm{O}\left(\mathrm{h}_{\mathrm{VB}}^{+}\right)+\mathrm{OH}^{-} \rightarrow \mathrm{OH}^{\bullet} \\
& \mathrm{Zn}_{1-x} \mathrm{Ce}_{x} \mathrm{O}\left(\mathrm{e}_{\mathrm{CB}}^{-}\right)+\mathrm{O}_{2} \rightarrow \mathrm{O}_{2}^{\bullet-} \\
& \mathrm{O}_{2}^{\bullet-}+\mathrm{H}^{+} \rightarrow \mathrm{HO}_{2}^{\bullet} \\
& 2 \mathrm{e}_{\mathrm{CB}}^{-}+\mathrm{HO}_{2}^{\bullet}+\mathrm{H}^{+} \rightarrow \mathrm{OH}^{\bullet}+\mathrm{OH}^{-}
\end{aligned}
$$




$$
\begin{aligned}
& \mathrm{OH}^{\bullet}, \mathrm{HO}_{2}^{\bullet}, \mathrm{O}_{2}^{\bullet-}+\mathrm{MB} \\
& \rightarrow \text { Degradation products }\left(\mathrm{CO}_{2}, \mathrm{H}_{2} \mathrm{O}\right)
\end{aligned}
$$

\section{Conclusion}

Ce-Doped $\mathrm{ZnO}$ nanoflowers were prepared by the microwaveassisted sol-gel method. The structural characterization of the samples by XRD showed the hexagonal wurtzite structure and also Ce-incorporation deteriorates the crystallinity. The energy dispersive X-ray spectra confirmed the elemental compositions in the $\mathrm{Ce}$-doped $\mathrm{ZnO}$ system. The optical band gap of the Ce-doped $\mathrm{ZnO}$ showed a red shift when compared with the undoped- $\mathrm{ZnO}$, which can be attributed to a charge transfer transition between the lanthanide ' $\mathrm{f}$ ' electrons of $\mathrm{Ce}$ and the $\mathrm{CB}$ or $\mathrm{VB}$ of the host $\mathrm{ZnO}$. PL measurements showed NBE UV emission and DL visible emission, and these emissions are closely related to the surface states, oxygen vacancies and defects. It is confirmed that the Ce dopant has a significant effect on structural, optical and photocatalytic properties. The PCD efficiency increased with an increase of Ce-dopant concentration, which indicated the applicability of Ce-doped $\mathrm{ZnO}$ in photocatalysis.

\section{References}

[1] Mo J, Hwang J E, Jegal J and Kim J 2007 Dye. Pig. 72240

[2] Deshmukh K, Ahmed M B, Deshmulh R R, Pasha S K K, Sadasivuni K K, Polu A R et al 2017 J. Mater. Sci.: Mater. Electron. 28973

[3] Ghazy M B, Esmail F A, El-Zawawy W K, Al-Maadeed M A and Owda M E $2016 \mathrm{~J}$. Adv. Chem. 123

[4] Al-Maadeed M A and Al-Thani R 2012 Int. J. Mater. Sci. Tech. 269

[5] Al-Maadeed M A, Shabana Y M and Noorunisha Khanam P 2014 Mater. Des. 581374

[6] Fayyad E M, Sadasivuni K K, Ponnamma D and Al-Maadeed M A 2016 Carbohydr. Polym. 151871

[7] Poornima Vijayan P and Al-Maadeed M A 2016 Exp. Polym. Lett. 10506

[8] Janson A, Minier-Matar J, Al-Shamari E, Hussain A, Sharma R, Rowley D et al 2018 Emerg. Mater. 177

[9] Basavaiah K, Kahsay M H and Rama Devi D 2018 Emerg. Mater. 1-2 121

[10] Liu H, Owen J S and Paul Alivisatos A 2007 J. Am. Chem. Soc. 129305

[11] Cao H, Zhao Y G, Ho S T, Seeling E W, Wang Q H and Chang R P H 1999 Phys. Rev. Lett. 822278

[12] Zhao J, Wang L, Yan X, Yang Y, Lei Y, Zhou J et al 2011 Mater. Res. Bull. 461207

[13] Nagaraj A, Govindaraj D and Rajan M 2018 Emerg. Mater. 1 25

[14] Jia T, Wang W, Long F, Fu Z, Wang H and Zhang Q 2009 J. Alloys Compd. $\mathbf{4 8 4} 410$

[15] Liu X, Zuo Y, Li L, Huang X and Li G 2014 RSC Adv. 46397

[16] Haase M, Riwotzki K, Meyssamy H and Kornowski A $2000 \mathrm{~J}$. Alloys Compd. $\mathbf{3 0 3} 191$
[17] Du Y P, Zhang Y W, Sun L D and Yan C H 2008 J. Phys. Chem. C 11212234

[18] Khatamian M, Khandar A A, Divband B, Haghigh M and Ebrahimias S 2012 J. Mol. Catal A: Chem. 365120

[19] Clament Sagaya Selvam N, Judith Vijaya J and John Kennedy L 2013 J. Colloid. Inter. Sci. 407215

[20] Sanoop P K, Anas S, Anadhakumar S, Gunasekar V, Saravanan R and Ponnusami V 2016 Arab. J. Chem. 9 S1618

[21] Mordkovich V Z, Hayashi H, Haemori M, Fukumura T and Kawasaki M 2003 Adv. Funct. Mater. 13519

[22] Cheng B, Xiao Y, Wu G and Zhang L 2004 Adv. Funct. Mater. 14913

[23] Li G R, Lu X H, Zhao W X, Su C Y and Tong Y X 2008 Cryst. Growth Des. 81276

[24] Hasnidawani J N, Azlina H N, Norita H, Bonia N N, Ratim S and Ali E S 2016 Proc. Chem. 19211

[25] Thomas D, Augustine S, Sadasivuni K K, Ponnamma D, Alhaddad A Y, Cabibihan J J et al 2016 J. Electron. Mater. 454847

[26] Thomas D, Thomas A, Tom A E, Sadasivuni K K, Ponnamma D, Goutham S et al 2017 Synth. Metals 232123

[27] Hezam A, Namratha K, Ponnamma D, Drmosh Q A, Saeed A M, Cheng C et al 2018 ACS Omega 312260

[28] Hezam A, Namratha K, Drmosh Q A, Ponnamma D, Saeed A M, Ganesh V et al 2018 Mater. Chem. A 621379

[29] Bilecka L and Niederberger M 2010 Nanoscale 41358

[30] Thomas D, Vijayalakshmi K A, Mathen J J, Augustine S, Ponnamma D, Sadasivuni K K et al 2017 Polym. Bull. 74 4989

[31] Tompsett G A, Conner W C and Yngvesson K S 2006 Chem. Phys. Chem. 7296

[32] Anandhababu G, Ravi G, Mahalingam T, Navaneethan M, Arivanandhan M and Hayakawa Y 2014 J. Phys. Chem. C 118 23335

[33] Hemalatha P, Karthick S N, Hemalatha K V, Yi M, Kim H J and Alagar M 2016 J. Mater. Sci.: Mater. Electron. 272367

[34] Papa F, Patron L, Carp O, Paraschir C and Ioan B 2009 J. Mol. Catal A: Chem. 29993

[35] Harish K N, Bhojya Naik H S, Prashanth Kumar P N and Viswanath R 2013 ACS Sustain. Chem. Eng. 11143

[36] Cullity B D and Stock S R 2001 Elements of X-ray diffraction, 2nd edn (Upper Saddle River: Prentice Hall)

[37] Humphreys F J and Ardakani M G 1996 Acta Mater. 442717

[38] Wang X, Zheng R, Liu Z, Ho H P, Xu J and Ringer S P 2008 Nanotechnology 19455702

[39] Hassan M M, Khan W, Azam A and Naqvi A H 2015 J. Ind. Eng. Chem. 21283

[40] Suwanboon S, Amornpitoksuk P, Sukolrat A and Muensit N 2013 Ceram. Int. 392811

[41] Shi H L and Duan Y 2008 Eur. Phys. J. B 66439

[42] Parangusan H, Ponnamma D, Al-Maadeed M A and Marimuthu A 2018 Photochem. Photobio. 94237

[43] Liu X, Sroppa D G, Heggan M, Ermolenko Y, Offenhausser A and Mourzina Y 2015 J. Phys. Chem. C 11910336

[44] Karunakaran C, Gomathisankar P and Manikandan G 2010 Mater. Chem. Phys. 123585

[45] Zhang H, Zong R, Zhu J and Zhu Y 2009 J. Phys. Chem. C 113 4605

[46] Divya N K and Pradyumnan P P 2017 J. Mater. Sci.: Mater. Electron. 282147

[47] Xu H, Li H, Xu L, Wu C, Sun G, Xu Y et al 2009 Ind. Eng. Chem. Res. 4810771 
[48] Liu I T, Hon M H and Tech L G 2014 Ceram. Int. 404019

[49] Chang C J, Lin C Y, Hsu M H and Taiwan J 2014 Inst. Chem. Eng. 451954

[50] Anandhababu G, Ravi G and Hayakawa Y 2015 Appl. Phys. A 119219

[51] Bohle D S and Spina C J 2009 J. Am. Chem. Soc. 1314397

[52] Vanheusden K, Seager C H, Warren W L, Tallent D R and Voigetr J A 1996 Appl. Phys. Lett. 68 403

[53] Singh A K, Viswanath V and Janu V C 2009 J. Lumin. 129 874

[54] Wong K W, Field N R, Ou J Z, Lathm L, Spencer M J, Yarovsky I et al 2010 Nanotechnology 23015705
[55] Choudhury B and Choudhury A 2012 Mater. Chem. Phys. 131 666

[56] Eskizeybek V, Fahriyesani B, Gulce H, Gulce A and Ahmet A 2012 Appl. Catal. B: Environ. 119197

[57] Li D and Haneda H 2003 Chemosphere 51129

[58] Tomar M S, Melgarejo R, Dobal P S and Katiyar R S $2001 \mathrm{~J}$. Mater. Res. 16903

[59] Cao Y, Yang W S, Chen Y M, Du H and Yue P 2004 Appl. Surf. Sci. 236223

[60] Liu Y, Kang Z H, Chen Z H, Shafiq I, Zapien J A, Bello I et al 2009 Cryst. Growth Des. 93222

[61] Kansal S K, Singh M and Sud D 2007 J. Hazard Mater. 141 581 